\title{
Distribution of Human Papillomavirus (HPV) Genotypes in HIV-Negative and HIV-Positive Women with Cervical Intraepithelial Lesions in the Eastern Cape Province, South Africa
}

\author{
Ongeziwe Taku ${ }^{1,2}$, Zizipho Z. A. Mbulawa ${ }^{1,3,4,5}$, Keletso Phohlo ${ }^{1,2}$, Mirta Garcia-Jardon ${ }^{6}$, Charles B. Businge ${ }^{7,8}$ \\ and Anna-Lise Williamson $1,2,3, *$ (D)
}

check for

updates

Citation: Taku, O.; Mbulawa, Z.Z.A.; Phohlo, K.; Garcia-Jardon, M.; Businge, C.B.; Williamson, A.-L. Distribution of Human

Papillomavirus (HPV) Genotypes in HIV-Negative and HIV-Positive Women with Cervical Intraepithelial Lesions in the Eastern Cape Province, South Africa. Viruses 2021, 13, 280. https://doi.org/10.3390/v13020280

Academic Editor: Ester Ballana Guix

Received: 23 December 2020

Accepted: 8 February 2021

Published: 11 February 2021

Publisher's Note: MDPI stays neutral with regard to jurisdictional claims in published maps and institutional affiliations.

Copyright: (c) 2021 by the authors. Licensee MDPI, Basel, Switzerland. This article is an open access article distributed under the terms and conditions of the Creative Commons Attribution (CC BY) license (https:/ / creativecommons.org/licenses/by/ $4.0 /)$.
1 Division of Medical Virology, Department of Pathology, Faculty of Health Sciences, University of Cape Town, Cape Town 7925, South Africa; tkxong001@myuct.ac.za (O.T.); Zizipho.Mbulawa@nhls.ac.za (Z.Z.A.M.); phhkel001@myuct.ac.za (K.P.)

2 Institute of Infectious Disease and Molecular Medicine, University of Cape Town, Cape Town 7925, South Africa

3 SAMRC Gynaecological Cancer Research Centre, University of Cape Town, Cape Town 7925, South Africa

4 Department of Laboratory Medicine and Pathology, Walter Sisulu University, Mthatha 5100, South Africa

5 National Health Laboratory Service, Nelson Mandela Academic Hospital, Mthatha 5100, South Africa

6 Department of Pathology, Walter Sisulu University and National Health Laboratory Service,

Mthatha 5100, South Africa; mirta@tiscali.co.za

7 Department of Obstetrics and Gynaecology, Nelson Mandela Academic Hospital, Mthatha 5100, South Africa; cbusingae@gmail.com

8 Department of Obstetrics and Gynaecology, Faculty of Health Sciences, Walter Sisulu University, Mthatha 5100, South Africa

* Correspondence: anna-lise.williamson@uct.ac.za; Tel.: +21-4066124

Abstract: South African women have a high rate of cervical cancer cases, but there are limited data on human papillomavirus (HPV) genotypes in cervical intraepithelial neoplasia (CIN) in the Eastern Cape province, South Africa. A total of 193 cervical specimens with confirmed CIN from women aged 18 years or older, recruited from a referral hospital, were tested for HPV infection. The cervical specimens, smeared onto FTA cards, were screened for $36 \mathrm{HPV}$ types using an HPV direct flow kit. HPV prevalence was 93.5\% (43/46) in CIN2 and 96.6\% (142/147) in CIN3. HIVpositive women had a significantly higher HPV prevalence than HIV-negative women $(98.0 \%$ vs. $89.1 \%, p=0.012$ ). The prevalence of multiple types was significantly higher in HIV-positive than HIVnegative women $(p=0.034)$. The frequently detected genotypes were HPV35 $(23.9 \%)$, HPV58 $(23.9 \%)$, HPV45 (19.6\%), and HPV16 (17.3\%) in CIN2 cases, while in CIN3, HPV35 (22.5\%), HPV16 (21.8\%), HPV33 (15.6\%), and HPV58 (14.3\%) were the most common identified HPV types, independent of HIV status. The prevalence of HPV types targeted by the nonavalent HPV vaccine was $60.9 \%$ and $68.7 \%$ among women with CIN2 and CIN3, respectively, indicating that vaccination would have an impact both in HIV-negative and HIV-positive South African women, although it will not provide full protection in preventing HPV infection and cervical cancer lesions.

Keywords: human papillomavirus; human immunodeficiency virus; cervical intraepithelial lesions; South Africa

\section{Introduction}

Human immunodeficiency virus (HIV) infection is highly predominant in Africa. Globally, approximately 25.7 million people live with HIV infection, of which $80 \%$ (20.7 million) reside in Eastern and Southern Africa, as reported in 2019 [1,2]. Of the African countries, South Africa has the largest population affected by HIV infection, with 7.5 million people living with HIV and 200,000 new infections reported in 2019 [3]. HIV prevalence is estimated to be $19.0 \%$ among women aged 15-49 years [2,3]. Among the nine provinces in 
South Africa, the prevalence of HIV infection for adult women aged 15-49 years ranges from $12.6 \%$ to $27.0 \%$, with high rates observed in Kwazulu-Natal province (27.0\%), Free State province (25.5\%), and Eastern Cape province (25.2\%) [4].

An interaction between HIV infection and specific cancers has been established. Cervical cancer is one of the three cancers established as AIDS-defining cancers [5]. South Africa ranked as the country with the fourth highest number of cervical cancer cases among HIVpositive women $(63.4 \%)$ in 2018 [6]. The incidence rate of cervical cancer was estimated to be 506 per 10,000 person-years among HIV-positive South African women in 2017 [7]. Cervical cancer arises from cervical intraepithelial neoplastic lesions (CIN) stages 1-3 and is causally associated with genital human papillomavirus (HPV) [8,9]. HIV-positive women have an increased burden of genital HPV acquisition, high-risk (HR) HPV persistent infection, multiple infections of HR-HPV, and precancerous lesions compared to HIV-negative women $[10,11]$. Studies suggest that this results from immune suppression and low CD4 cell count $[10,12]$.

Persistent infection with HPV16, HPV18, and other HR-HPV genotypes is the most significant risk factor for developing cervical lesions and cervical cancer [13]. HPV16/18 are essential HR-HPV types that significantly contribute to cervical cancer disease progression [14]. There are different strategies implemented to prevent preinvasive lesions and cervical cancer, mainly through HPV vaccination and cervical cancer screening. The typespecific HPV vaccines, namely, bivalent (HPV16/18), quadrivalent (HPV16/18/6/11), and nonavalent (HPV16/18/6/11/31/33/45/52/58), have been introduced in more than forty countries, both developing and developed [15-17]. These vaccines are offered to adolescent and young women aged 9-26 years $[15,16]$. In South Africa, a national school-based vaccination campaign for the bivalent HPV vaccine was implemented to target public school girls aged nine years in grade 4 . An uptake of the bivalent HPV vaccine ranging from $87 \%$ to $92 \%$ was positively attained among South African girls [18,19]. However, cervical cancer screening among older women is still necessary, as they are beyond the targeted age for receiving the HPV vaccine and more likely to have been infected with HPV.

Molecular HPV DNA testing has been implemented as the alternative to non-molecular testing for cervical cancer, particularly cytology testing [20]. HPV testing is utilised in various strategies for screening, such as triage, co-testing, or HPV testing alone [21], and has high sensitivity but low specificity for the detection of CIN2/3 [22,23].

There is limited information on the epidemiology of HPV types in women with preinvasive cervical lesions from the Eastern Cape province. It is essential to investigate the prevalence of HPV genotypes and their distribution among women with different immune statuses and confirmed CIN histology results in this region. Therefore, these data will help achieve better understanding of the HR-HPV types involved in cervical lesions and cervical cancer cases. Furthermore, this information will contribute to discussions about implementing strategies for cervical screening and monitoring HPV types that are not present in the current vaccines to reduce cervical cancer disease in this population. Our study aims at investigating the distribution of HPV genotypes among HIV-positive and HIV-negative women with cervical intraepithelial lesions from Eastern Cape, South Africa.

\section{Material and Methods}

\subsection{Study Population}

The study obtained ethical approval from the Human Ethics Committees of the University of Cape Town (UCT, HREC reference 615/2017), Walter Sisulu University (016/2017), and Eastern Cape Department of Health (EC reference 2017RPO_484). The recruitment procedure for this study was reported previously [24]. Briefly, between September 2017 and March 2019, cervical specimens were collected among women referred to the Nelson Mandela Academic Hospital Gynaecology Outpatient Clinic located in the OR Tambo municipality area in the Eastern Cape province, South Africa. A total of 193 women were recruited, aged $\geq 18$ years, with atypical squamous cells of undetermined significance (ASCUS), atypical squamous cells cannot exclude high-grade lesions (ASC-H), atypical 
glandular cells, not otherwise specified (AGC-NOS), low-grade squamous intraepithelial lesions (LSIL), and high-grade squamous intraepithelial lesions (HSIL). The cervical specimens were collected by a study nurse using a Viba-brush (Rovers Medical Devices B.V., 5347 KV Oss, Netherlands, smeared onto FTA cards (GE Healthcare, Amersham place little Chalfont, Buckinghamshire HP7 9NA, UK), and shipped at room temperature to UCT. The cervical biopsy was collected for histopathology and was performed by the National Health Laboratory Service. Based on the histopathology results, 46 women with CIN2 and 147 with CIN3 were included in this study. All eligible women provided signed consent forms.

\subsection{Detection of HPV Genotypes}

DNA elution of cervical specimens from FTA cards was done following the procedure previously described [24,25]. Four microlitres of extracted DNA was used for HPV testing. Detection of HPV genotypes was performed using an HPV direct flow chip kit on a Hybrispot machine (Master Diagnostica, Granada, Spain) following the manufacturer's procedure. The HPV direct flow chip protocol is a PCR-based method based on the amplification of a viral DNA fragment, followed by hybridisation onto a membrane chip using the amplified PCR products. The chip membrane contains DNA control, hybridisation control, PCR control, and probes for genotype-specific HPV detection. The assay detects 36 HPV genotypes (low-risk HPV: 6, 11, 40, 42, 43, 44, 54, 55, 61, 62, 67, 69, 70, 71, 72, 81, 84, and 89 (C6108) and high-risk HPV:16, 18, 26, 31, 33, 35, 39, 45, 51, 52, 53, 56, 58, 59, 66, 68,73 and 82 ). Each chip membrane's results were captured by a camera and analysed automatically using HybriSoft software (Master Diagnostica, Granada, Spain) [26].

\subsection{Data Analysis}

All data and statistical analyses were done using GraphPad Prism version 6 (GraphPad Software, La Jolla, CA, USA). The chi-squared test was used to determine a statistical difference between HPV infection and variables. A variable was considered significant if the $p$-value was $<0.05$.

\section{Results}

\subsection{Description of Study Participants}

The median age of women was 40 (IQR: 33-48) years. A high number of women were HIV-positive (76.2\%) and never smoked (93.3\%), and half of the women had their first sexual experience at the age of $16-18$ years $(53.9 \%)$ (Table 1$)$. Women were more likely to have $\geq 3$-lifetime sexual partners $(62.7 \%)$, with a high proportion having high-grade squamous lesions on cytology testing $(75.1 \%)$ (Table 1$)$.

\subsection{HPV Prevalence According to HIV Status}

Of the 193 women screened, 93.5\% (43/46) with CIN2 and 96.6\% with CIN3 had an HPV infection. HIV-positive women had a significantly higher prevalence of any HPV infection compared to HIV-negative women $(98.0 \%$ vs. $89.1 \%, p=0.012)$ (Table 2$)$. HIVnegative women were almost 2-times more likely to have only a single HPV infection compared to HIV-positive women, although there was no statistical significance (OR: 1.45; CI: $0.735-2.867, p=0.282$, Table 2). However, HIV-positive women had a significantly higher HPV prevalence compared to HIV-negative women $(65.3 \%$ vs. $47.8 \%, p=0.034$, Table 2). For multiple infections, the median of HPV types was 2 (range: 2-11). When stratified by HIV status, there was no significant distinction between HIV-negative and HPV-positive women (Figure 1). 
Table 1. Demographic and behavioural characteristics of study participants.

\begin{tabular}{|c|c|}
\hline Variables & $\%(\mathrm{n} / \mathrm{N})$ \\
\hline Age in years: Median (IQR) & $40(33-48)$ \\
\hline \multicolumn{2}{|l|}{ HIV Status } \\
\hline No & $23.8 \%(46 / 193)$ \\
\hline Yes & $76.2 \%(147 / 193)$ \\
\hline \multicolumn{2}{|l|}{ Age categories } \\
\hline $18-29$ years & $11.4 \%(22 / 193)$ \\
\hline 30-39 years & $35.2 \%(68 / 193)$ \\
\hline $40-49$ years & $35.2 \%(68 / 193)$ \\
\hline$\geq 50$ years & $18.1 \%(35 / 193)$ \\
\hline \multicolumn{2}{|l|}{ Highest level of education attained } \\
\hline Never/primary & $29.5 \%(57 / 193)$ \\
\hline High school/university & $70.5 \%(136 / 193)$ \\
\hline \multicolumn{2}{|l|}{ Household income } \\
\hline$<\$ 139.36$ & $75.1 \%(145 / 193)$ \\
\hline$\geq \$ 139.36$ & $22.8 \%(44 / 193)$ \\
\hline \multicolumn{2}{|l|}{ Smoking status } \\
\hline Never & $93.3 \%(180 / 193)$ \\
\hline Former/current smoker & $6.2 \%(12 / 193)$ \\
\hline \multicolumn{2}{|l|}{ Age at first sexual experience } \\
\hline$<16$ years & $21.2 \%(41 / 193)$ \\
\hline $16-18$ years & $53.9 \%(104 / 193)$ \\
\hline$\geq 18$ years & $24.9 \%(48 / 193)$ \\
\hline \multicolumn{2}{|l|}{ Lifetime sexual partners } \\
\hline 1 & $15.0 \%(29 / 193)$ \\
\hline 2 & $21.8 \%(42 / 193)$ \\
\hline$\geq 3$ & $62.7 \%(121 / 193)$ \\
\hline \multicolumn{2}{|l|}{ Cytology } \\
\hline ASCUS/ASCU-H/AGC-NOS & $13.5 \%(26 / 193)$ \\
\hline LSIL & $9.3 \%(18 / 193)$ \\
\hline HSIL & $75.1 \%(145 / 193)$ \\
\hline
\end{tabular}

ASCUS: atypical squamous cells of undetermined significance; ASC-H: atypical squamous cells cannot exclude high-grade lesions; AGC-NOS: atypical glandular cells, not otherwise specified; LSIL: low-grade squamous intraepithelial lesions; HSIL: high-grade squamous intraepithelial lesions.

Table 2. Prevalence of HPV infection according to HIV status.

\begin{tabular}{ccccc}
\hline Variables & HIV-Negative, N = 46 & HIV-Positive, N = 147 & OR (95\%CI) & $p$-Value \\
\hline Any type & $89.1 \%(41 / 46)$ & $98.0 \%(144 / 147)$ & $0.17(0.039-0.745)$ & 0.012 \\
Single infection & $41.3 \%(19 / 46)$ & $32.7 \%(48 / 147)$ & $1.45(0.735-2.867)$ & 0.282 \\
Multiple infection & $47.8 \%(22 / 46)$ & $65.3 \%(96 / 147)$ & $0.49(0.249-0.953)$ & 0.034 \\
HR-HPV types & $82.6 \%(38 / 46)$ & $87.1 \%(128 / 147)$ & $0.71(0.286-1.738)$ & 0.446 \\
Probable HR-HPV & $17.4 \%(8 / 46)$ & $30.6 \%(45 / 147)$ & $0.60(0.260-1.394)$ & 0.233 \\
types & $39.1 \%(18 / 46)$ & $44.2 \%(65 / 147)$ & $0.81(0.413-1.594)$ & 0.543 \\
LR-HPV & &
\end{tabular}

HR-HPV: high-risk human papillomavirus; LR-HPV: low-risk human papillomavirus; OR: odds ratio; CI: confidence intervals.

\subsection{HPV Distribution According to Cervical Intraepithelial Lesions and HIV Status}

Women with CIN2 were more likely to be infected with two HPV types (Figure 2A). The most frequently detected HPV types were HPV35 (23.9\%), HPV58 (23.9\%), HPV45 (19.6\%), and HPV16 (17.3\%) (Table 3). Among single HPV infections, HPV35 and HPV16 were more frequent in HIV-negative women, while HPV16 and HPV52 were detected in HIV-positive women (Figure 3). For multiple HPV infections, HPV35, HPV58, and HPV45 were common in HIV-positive women, whereas HPV35, HPV58, and HPV16 were frequently detected among HIV-negative women (Figure 3). 

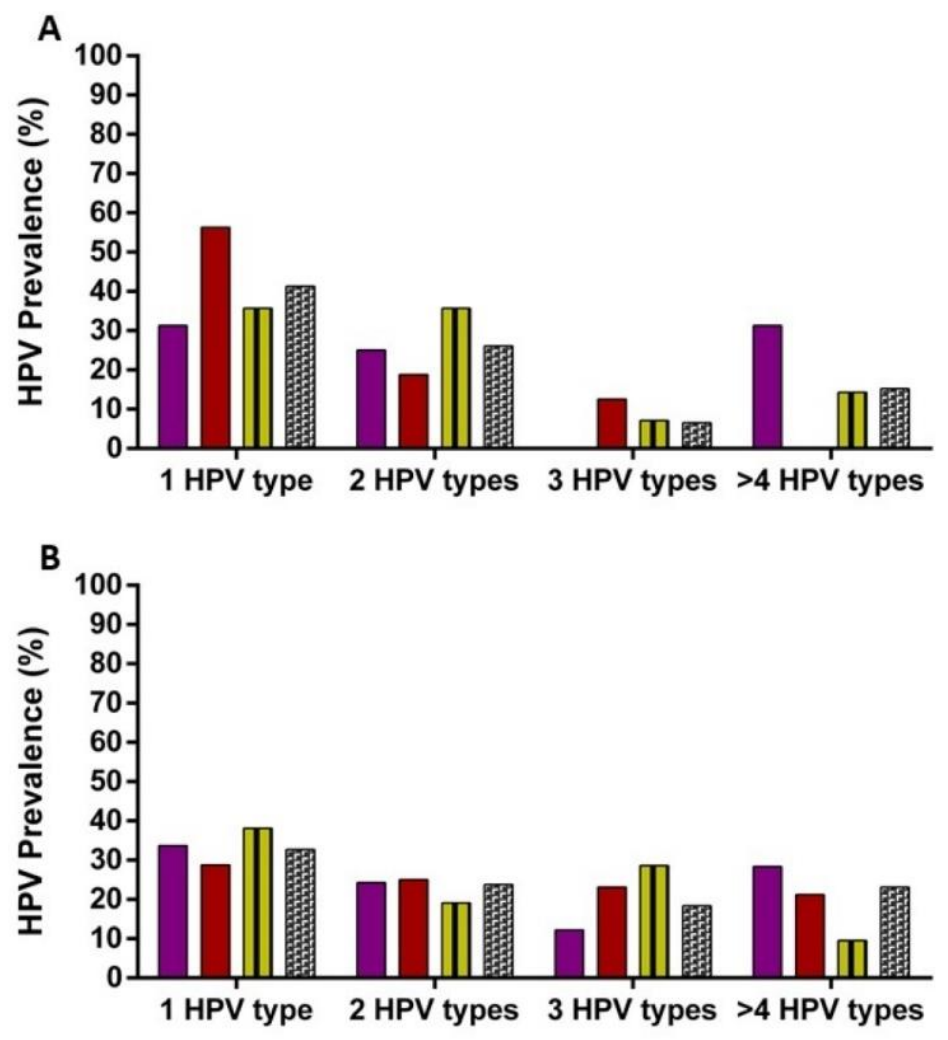

- 40 years, $\mathrm{N}=16$

40-49 years, $N=16$

III $\geq 50$ years, $N=14$

All women, $\mathrm{N}=46$

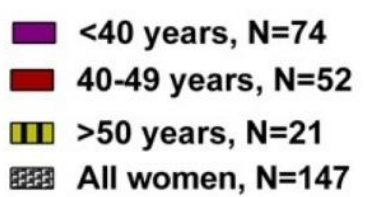

Figure 1. Distribution of single and multiple HPV types according to age in HIV-negative (A) and HIV-positive (B) women with cervical intraepithelial lesions.

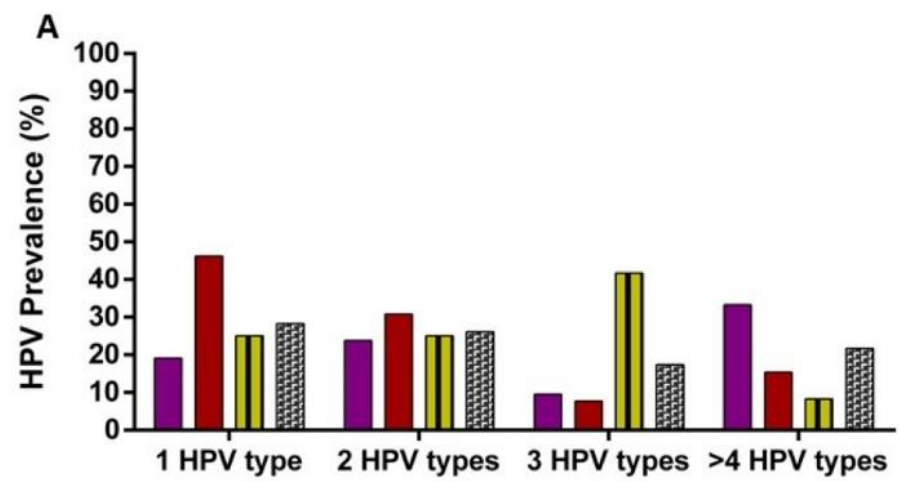

$<40$ years, $\mathrm{N}=\mathbf{2 1}$

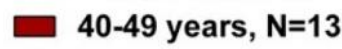

III $\geq 50$ years, $\mathrm{N}=12$

All women, $\mathrm{N}=46$

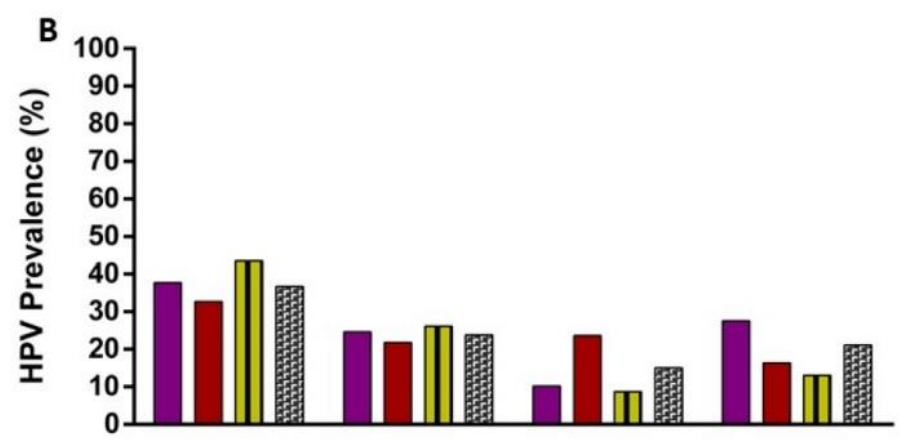

$<40$ years, $\mathrm{N}=69$

40-49 years, $\mathrm{N}=55$

III $\geq \mathbf{5 0}$ years, $\mathrm{N}=\mathbf{2 3}$

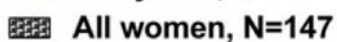

Figure 2. Distribution of single and multiple HPV types according to age in women with CIN2 (A) and CIN3 (B). 
Table 3. Distribution of HPV genotypes among women with CIN2 and CIN3 from a referral hospital.

\begin{tabular}{|c|c|c|c|}
\hline HPV Types & All Women \% (n/N) & CIN2 \% (n/N) & CIN3 \% (n/N) \\
\hline 16 & $20.7 \%(40 / 193)$ & $17.4 \%(8 / 46)$ & $21.8 \%(32 / 147)$ \\
\hline 18 & $8.8 \%(17 / 193)$ & $10.9 \%(5 / 46)$ & $8.8 \%(12 / 147)$ \\
\hline 31 & $11.4 \%(22 / 193)$ & $8.7 \%(4 / 46)$ & $12.2 \%(18 / 147)$ \\
\hline 33 & $13.0 \%(25 / 193)$ & $4.4 \%(2 / 46)$ & $15.6 \%(23 / 147)$ \\
\hline 35 & $22.8 \%(44 / 193)$ & $23.9 \%(11 / 46)$ & $22.5 \%(33 / 147)$ \\
\hline 39 & $6.2 \%(12 / 193)$ & $2.2 \%(1 / 46)$ & $7.5 \%(11 / 147)$ \\
\hline 45 & $15.0 \%(29 / 193)$ & $19.6 \%(9 / 46)$ & $13.6 \%(20 / 147)$ \\
\hline 51 & $6.7 \%(13 / 193)$ & $6.5 \%(3 / 46)$ & $6.8 \%(10 / 147)$ \\
\hline 52 & $13.5 \%(26 / 193)$ & $15.2 \%(7 / 46)$ & $12.9 \%(19 / 147)$ \\
\hline 56 & $8.3 \%(16 / 193)$ & $4.4 \%(2 / 46)$ & $9.5 \%(14 / 147)$ \\
\hline 58 & $16.6 \%(32 / 193)$ & $23.9 \%(11 / 46)$ & $14.3 \%(21 / 147)$ \\
\hline 59 & $2.6 \%(5 / 193)$ & $4.4 \%(2 / 46)$ & $2.0 \%(3 / 147)$ \\
\hline 26 & $4.1 \%(8 / 193)$ & $4.4 \%(2 / 46)$ & $4.1 \%(6 / 147)$ \\
\hline 53 & $0.5 \%(1 / 193)$ & $0.0 \%(0 / 46)$ & $0.7 \%(1 / 147)$ \\
\hline 66 & $8.3 \%(16 / 193)$ & $8.7 \%(4 / 46)$ & $8.2 \%(12 / 147)$ \\
\hline 68 & $4.1 \%(8 / 193)$ & $4.4 \%(2 / 46)$ & $4.1 \%(6 / 147)$ \\
\hline 73 & $2.6 \%(5 / 193)$ & $4.4 \%(2 / 46)$ & $2.0 \%(3 / 147)$ \\
\hline 82 & $10.4 \%(20 / 193)$ & $6.5 \%(3 / 46)$ & $11.6 \%(17 / 147)$ \\
\hline 6 & $6.2 \%(12 / 193)$ & $6.5 \%(3 / 46)$ & $6.1 \%(9 / 147)$ \\
\hline 11 & $4.7 \%(9 / 193)$ & $0.0 \%(0 / 46)$ & $6.1 \%(9 / 147)$ \\
\hline 40 & $3.6 \%(7 / 193)$ & $2.2 \%(1 / 46)$ & $4.1 \%(6 / 147)$ \\
\hline 42 & $7.3 \%(14 / 193)$ & $8.7 \%(4 / 46)$ & $6.8 \%(10 / 147)$ \\
\hline 43 & $2.1 \%(4 / 193)$ & $0.0 \%(0 / 46)$ & $2.7 \%(4 / 147)$ \\
\hline $44 / 55$ & $10.9 \%(21 / 193)$ & $17.4 \%(8 / 46)$ & $8.8 \%(13 / 147)$ \\
\hline 54 & $3.6 \%(7 / 193)$ & $6.5 \%(3 / 46)$ & $2.7 \%(4 / 147)$ \\
\hline 61 & $0.5 \%(1 / 193)$ & $0.0 \%(0 / 46)$ & $1.4 \%(1 / 147)$ \\
\hline $62 / 81$ & $15.0 \%(29 / 193)$ & $19.6 \%(9 / 46)$ & $13.6 \%(20 / 147)$ \\
\hline 70 & $4.1 \%(8 / 193)$ & $6.5 \%(3 / 46)$ & $3.4 \%(5 / 147)$ \\
\hline 71 & $4.7 \%(9 / 193)$ & $2.2 \%(1 / 46)$ & $5.4 \%(8 / 147)$ \\
\hline 72 & $3.6 \%(7 / 193)$ & $6.5 \%(3 / 46)$ & $2.7 \%(4 / 147)$ \\
\hline
\end{tabular}

HPV: human papillomavirus; CIN: cervical intraepithelial neoplasia. Bold indicates the most dominant HPV types.

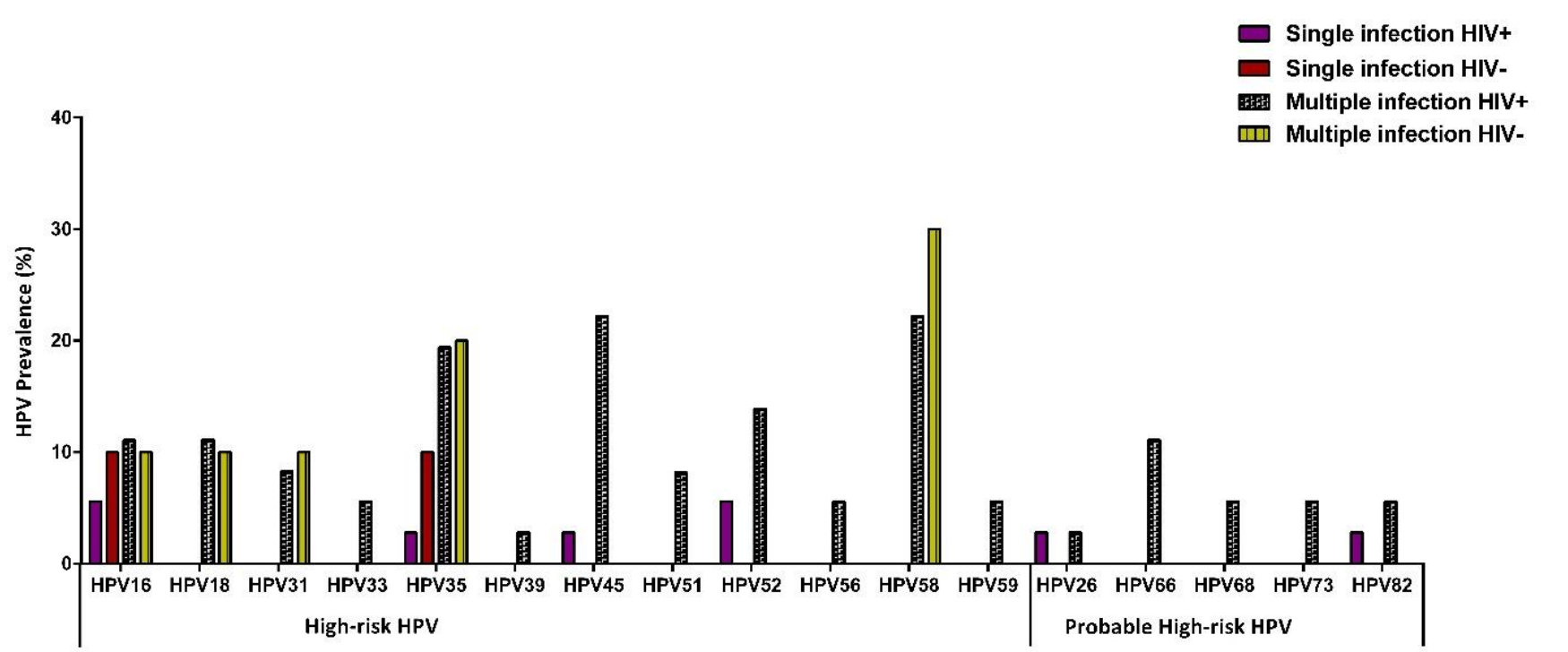

Figure 3. Distribution of HPV types among women with CIN2 in single and multiple infections according to HIV status.

Women with CIN3 were more likely to be infected with two HPV types (Figure 2B). Their commonly identified HPV types were HPV35 (22.5\%), HPV16 (21.8\%), HPV33 (15.6\%), and HPV58 (14.3\%) (Table 3). In single infections, HPV16, HPV35, and HPV33 were mostly observed in HIV-negative and HIV-positive women (Figure 4). However, the most 
detected HPV types in multiple infections were HPV16, HPV35, and HPV66 in HIVnegative, whereas HPV16, HPV35, and HPV45 were observed among HIV-positive women (Figure 4).

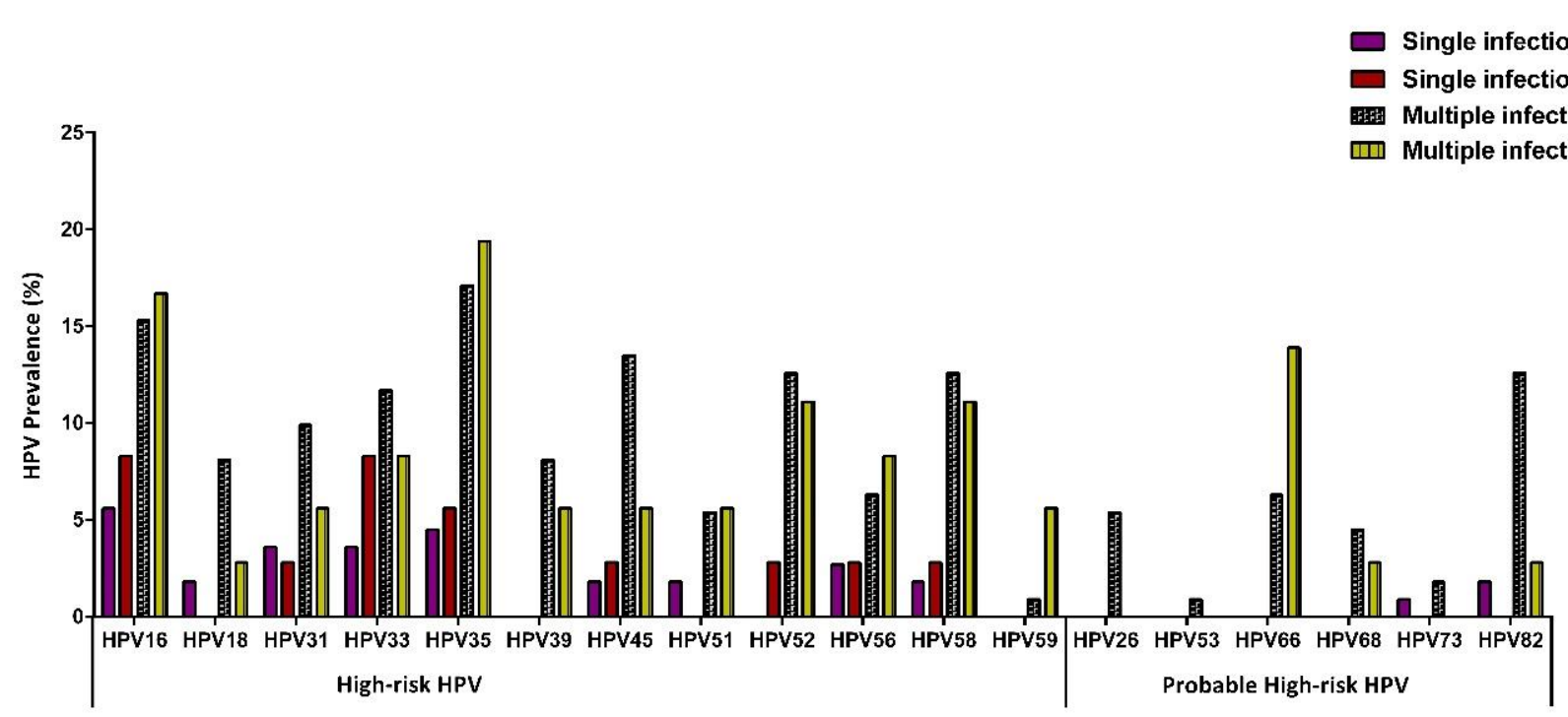

Figure 4. Distribution of HPV types among women with CIN3 in single and multiple infections according to HIV status.

\subsection{HPV Prevalence According to Vaccine HPV Types}

The prevalence of bivalent vaccine HPV types (HPV16/18) increased from $20.0 \%$ of CIN2/HIV-negative to $25.0 \%$ of CIN2/HIV-positive and from $27.8 \%$ of CIN3/HIV-negative to $29.7 \%$ of CIN3/HIV-positive, with no statistical significance $(p=1.000$ and $p=0.823$, respectively) (Figure 5). For quadrivalent HPV types (HPV6/11/16/18), the positivity increased from $20.0 \%$ for CIN2/HIV-negative to $30.5 \%$ for CIN2/HIV-positive and from $33.3 \%$ for CIN3/HIV-negative to $36.0 \%$ for CIN3/HIV-positive $(p=0.700$ and $p=0.768$, respectively) (Figure 5). CIN2/HIV-positive women had a higher prevalence of nonavalent HPV types than CIN2/HPV-negative, with no statistical significance (66.7\% vs. $40.0 \%$, $p=0.157)$. However, CIN3/HIV-negative women had a similar prevalence of nonavalent HPV types (HPV6/11/16/18/31/33/45/52/58) to CIN3/HIV-positive women $(67.7 \%$ vs. $69.0 \%, p=0.761$ ) (Figure 5).

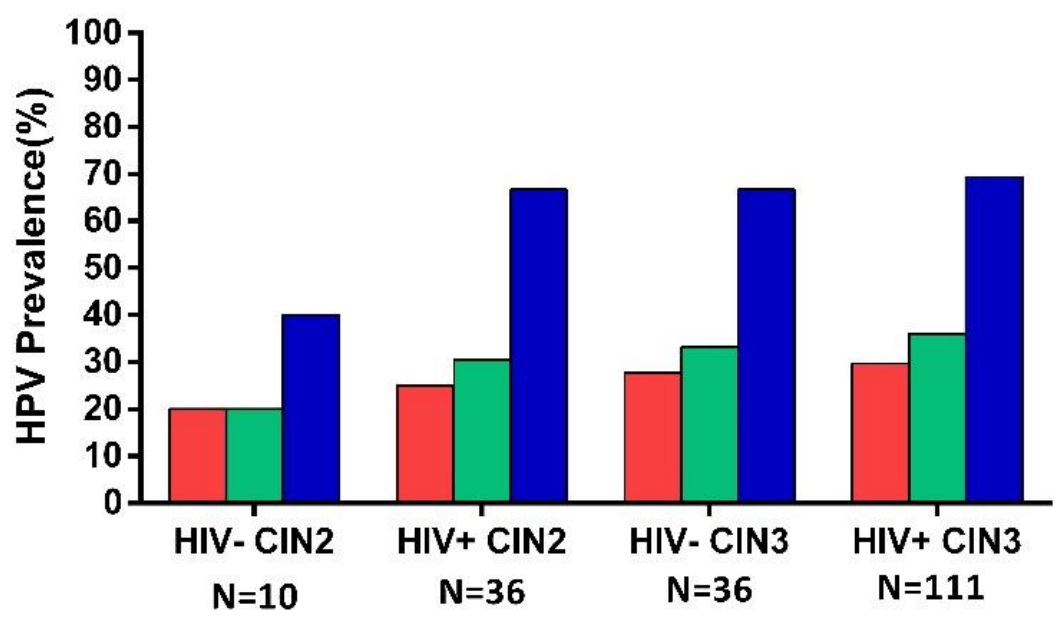

Bivalent

Quadrivalent

Nonavalent

Figure 5. Prevalence of HPV vaccine types according to CIN2/3 and HIV status. 


\section{Discussion}

This study investigated the prevalence and distribution of HPV types among HIVpositive and HIV-negative women with high-grade precancerous cervical lesions. A high number of women in this study were HIV-positive (76.2\%). A significantly high overall prevalence of any HPV infection (98\% vs. $89 \%$ ) and multiple infections (65\% vs. $49 \%)$ was observed among HIV-positive compared to HIV-negative women with cervical intraepithelial lesions. This higher prevalence of multiple types of HPV infection among women with HIV infection agrees with other cohorts of women with high-grade lesions from Botswana and South Africa [27-29]. However, in a South African study by Van Aardt and colleagues (2016), the rate of multiple HPV infections among HIV-positive and HIV-negative women ( $81.3 \%$ vs. $64.4 \%$ ) with confirmed CIN2/3 was higher compared to our study [29]. This difference could be attributed to the various assays used for HPV testing and the different study populations.

A high prevalence of HPV in women with CIN2 (93.5\%) and CIN3 (96.6\%) was observed in this study, which is expected as these women had abnormal cytology from the referral clinic. Similarly, a high HPV prevalence was reported in a global meta-analysis study, whereby HPV prevalence ranged from $86 \%$ to $93 \%$ in women with high-grade lesions (CIN2/3) [30]. In the present cohort, HPV35 was the most predominant HPV type among participants with CIN2 lesions, while in those with CIN3 lesions, HPV16 and HPV35 were the most frequently detected HPV genotypes, either as a single HPV infection or multiple infections, regardless of HIV status. This observation was similar to other studies from South Africa and Kenya, where HPV16 and 35 were the most common genotypes in HIV-positive or HIV-negative women with high-grade squamous intraepithelial lesions or CIN2/3 [28,31]. However, a study among sex workers from Kenya showed that HPV52 was the most prevalent HPV type and more likely to be present as a single infection in women with severe lesions (HSIL/SCC) [32]. Furthermore, a recent cross-sectional study by Dovey (2018) among women from four developed countries (Iceland, Norway, Sweden, and Denmark) reported a different distribution of HPV types, with HPV16, 31, and 52 present in CIN2 cases and HPV 16, 31, and 33 detected in CIN3 cases [33]. The high occurrence of HPV35 in this population and other African studies of women with invasive cervical cancer suggests an interaction between HPV35 and cervical carcinogenesis [34-36]. Therefore, preventative strategies are needed, as the HPV35 genotype is present in up to $10 \%$ of sub-Saharan African women with invasive cervical cancer [36-39] and not present in the current HPV vaccines.

Previously, cervical histological lesions were associated with one HPV type [40]. However, in the present cohort, most high-risk HPV types and probable high-risk HPV types occurred as multiple HPV infections both in CIN2 and CIN3 cases. Multiple infections are reported as the risk factor of persistent infection and associated with high-grade CIN2/3 cases compared to a single infection [41]. Women with multiple HPV types have been found to have larger cervical lesions and are associated with poor responses to cervical cancer treatment [42,43]. Kaliff et al. (2018) reported a significantly high recurrence rate of cervical cancer among women with multiple HPV infections compared to a single HPV infection $(44.0 \%$ vs. $24.0 \%)$ and a low cancer survival rate [42]. Furthermore, the high prevalence of multiple HPV infections in the present study could be because HPV testing was performed on cervical cells instead of biopsy specimens. Therefore, it is not possible to determine which HPV types caused the lesion and which infected other parts of the cervix. HPV testing on biopsies eliminates the detection of multiple HPV infections, and multiple $\mathrm{HPV}$ infections are observed to be significantly lower in biopsies compared to exfoliated cells from invasive cervical cancers [39,44].

Interestingly, in our study, HPV16 was not the predominant HPV type, as it ranked fourth in CIN2 and second in CIN3 cases in the present cohort. A low prevalence of HPV16 has been observed in other sub-Saharan studies, while a high prevalence was observed in European studies [45-47]. These findings could be explained by the population being sampled from different geographical areas, host genetic difference/host immunogenic 
factors, and the biological interplay between HPV types [48]. It is important to do a study based on cervical cancer biopsies to determine which HPV types are causally involved in cervical cancer in this community. The distribution of HPV types in this study are concerning, as there are many types that are not in the available vaccines.

Persistent HR-HPV infection is regarded as a significant factor in the development of cervical cancer lesions. However, in the current study, 4.2\% (8/193) of women with CIN2/3 were negative for any HPV type, and seven of these samples were also negative when typed with $h p V I R$ real-time PCR [24]. One specimen was positive on $h p V I R$ real-time PCR for HR-HPV infection (HPV59) but had a low HPV copy number (11.3 copies) and viral titre (0.052). The observed negative results of HPV infection in women with high-grade lesions may suggest that it could result from sample storage, inadequate sampling, or low viral load. Alternatively, there may be novel HPV types causing the cancers that are not detected by the test used.

The currently available HPV vaccines are estimated to prevent $70-90 \%$ of cervical cancer cases [49]. The nonavalent HPV vaccine has been highly effective in preventing HPV infection and cancer diseases, with efficacies ranging between $90 \%$ and $100 \%$ [15,50-52]. A study reported by Garland and colleagues (2018) in Asian women showed that nonavalent significantly decreased the risk of persistent infection, abnormal cytology, and diseases caused by specific HPV types targeted by this vaccine [50]. In the present study, HPV vaccines could protect $20-69.0 \%$ of CIN2/3 cases in women with or without HIV infection. Therefore, the high prevalence of HPV types targeted by the nonavalent HPV vaccine suggests that introducing this HPV vaccine would be beneficial, as most precancerous lesions could have been prevented. However, the predominant HPV genotype (HPV35) in this population, which accounts for $24 \%$ in CIN2 and $23.0 \%$ in CIN3, is not covered by the nonavalent HPV vaccine.

Vaccines have been found to provide cross-protection against specific vaccine HPV types as well as some types that are not present in the vaccine. Numerous trial studies have reported that the bivalent vaccine offers a wider extent of cross-protection against nonvalent specific types $(31 / 33 / 45 / 52 / 58)$, with less extensive cross-protection by Gardasil9 [53-55]. Studies have reported that bivalent showed substantial cross-protection against HPV31/33/45 but less so against HPV35 and HPV58 after seven to eight years postvaccination $[53,56,57]$. A study by Brown and colleagues (2009) among younger women aged 1625 years vaccinated with the quadrivalent $\mathrm{HPV}$ vaccine showed a reduction of high-grade lesions (32.5\%) related to ten non-vaccine HPV types (31/33/35/39/45/52/52/56/58/59) known to cause cervical cancer after 3.6 years of follow-up [58]. Therefore, this suggests that cross-protection might have played a role and that the benefits of vaccination could include protection from clinically relevant HPV types not included in the vaccines [58]. The cross-protection is related to the phylogenetic distance between the HPV types, as they are all closely related to vaccine types and found in the alpha-9 group [56]. However, since cross-protection against HPV35 is observed to be less efficient compared to other HPV types, the addition of HPV35 to the next-generation HPV vaccine would improve the effectiveness of the HPV vaccine, especially in Africa.

\section{Conclusions}

We observed a significantly higher prevalence of HPV and multiple HPV infections in HIV-positive compared to HIV-negative women with cervical intraepithelial lesions. The distribution of HPV genotypes was similar between CIN2 and CIN3 cases independently of HIV status. The HPV nonavalent vaccine would have an impact on South African women, although it will not provide full protection in preventing HPV infection and cervical cancer lesions. Therefore, the high prevalence of the non-vaccine type (HPV35) underscores the need to incorporate this HPV type into the next HPV vaccines. This study also highlights the importance of introducing cervical cancer screening strategies to monitor non-vaccine HPV types. 
Author Contributions: A.-L.W., Z.Z.A.M., C.B.B., K.P., M.G.-J., and O.T. were responsible for the conception, design of the study, and specimen collection. O.T. was responsible for specimen storage and performing the experiments for the study. Analysis and interpretation of data were performed by O.T., C.B.B. and M.G.-J. were responsible for the interpretation of histology analysis. The first draft of the paper was written by O.T. with the contribution of A.-L.W. and Z.Z.A.M. All authors were actively involved in interpreting the data, revising the manuscript, and approved the final version of the manuscript to be submitted. Opinions, findings, and conclusions or recommendations are those of the authors alone and do not reflect NRF opinions. All authors have read and agreed to the published version of the manuscript.

Funding: This work was supported in part by the National Research Foundation of South Africa (Grant Numbers: 64815), Poliomyelitis Research Foundation (PRF) and South African Medical Research Council-FORTE (SAMRC-FORTE).

Institutional Review Board Statement: The study was conducted according to the guidelines of the Declaration of Helsinki and approved by the Human research Ethics Committee of the University of Cape Town (UCT, HREC reference 615/2017), Walter Sisulu University (016/2017), and Eastern Cape Department of Health (EC reference 2017RPO_484).

Informed Consent Statement: All eligible women provided signed consent forms.

Data Availability Statement: The data analysed in this study is available upon request from the corresponding author.

Acknowledgments: We thank the Community clinic staff members, Sr Virginia Maqoga, Luviwe Lutotswana, and women who kindly participated in the study.

Conflicts of Interest: All authors declare no conflict of interests.

\begin{abstract}
Abbreviations
HPV: human papillomavirus, HIV: human immunodeficiency virus, CIN: cervical intraepithelial lesion, HR-HPV: high-risk HPV, UCT: university of Cape Town, HSIL: high grade squamous intraepithelial lesions, SCC: squamous cell carcinoma.
\end{abstract}

\title{
References
}

1. Avert. HIV and AIDS in East and Southern Africa Regional Overview. 2019. Available online: https://wwwavertorg/printpdf/ node/393 (accessed on 31 October 2020).

2. WHO. HIV/AIDS: Data and Statistics. 2019. Available online: https:/ / wwwwhoint/hiv/data/en/ (accessed on 31 October 2020).

3. UNAIDS. Aidsinfo. 2019. Available online: http://aidsinfounaidsorg/ (accessed on 31 October 2020).

4. Human Sciences Research Council H. The Fifth South African National HIV Prevalence, Incidence, Behaviour and Communication Survey; HIV Impact Assessment Summary Report Cape Town; HSRC Press: Cape Town, South Africa, 2018.

5. Blattner, W.A.; Nowak, R.G. Epidemiology of AIDS-Defining Malignancies. In Encyclopedia of AIDS; Hope, T.J., Stevenson, M., Richman, D., Eds.; Springer: New York, NY, USA, 2013; pp. 1-12.

6. Stelzle, D.; Tanaka, L.F.; Lee, K.K.; Khalil, A.I.; Baussano, I.; Shah, A.S.V.; McAllister, D.A.; Gottlieb, S.L.; Klug, S.J.; Winkler, A.S.; et al. Estimates of the global burden of cervical cancer associated with HIV. Lancet Glob. Health 2020, 9, e161-e169. [CrossRef]

7. Rohner, E.; Sengayi, M.; Goeieman, B.; Michelow, P.; Firnhaber, C.; Maskew, M.; Bohlius, J. Cervical cancer risk and impact of Pap-based screening in HIV-positive women on antiretroviral therapy in Johannesburg, South Africa. Int. J. Cancer 2017, 141, 488-496. [CrossRef]

8. Zur Hausen, H. Papillomaviruses and cancer: From basic studies to clinical application. Nat. Rev. Cancer 2002, 2, 342-350. [CrossRef]

9. Jemal, A.; Bray, F.; Center, M.M.; Ferlay, J.; Ward, E.; Forman, D. Global cancer statistics. CA Cancer J. Clin. 2011, 61, 69-90. [CrossRef] [PubMed]

10. Liu, G.; Sharma, M.; Tan, N.; Barnabas, R.V. HIV-positive women have higher risk of human papilloma virus infection, precancerous lesions, and cervical cancer. AIDS 2018, 32, 795-808. [CrossRef] [PubMed]

11. Marembo, T.; Mandishora, R.D.; Borok, M. Use of Multiplex Polymerase Chain Reaction for Detection of High-Risk Human Papillomavirus Genotypes in Women Attending Routine Cervical Cancer Screening in Harare. Intervirology 2019, $62,90-95$. [CrossRef] [PubMed]

12. Kriek, J.-M.; Jaumdally, S.Z.; Masson, L.; Little, F.; Mbulawa, Z.; Gumbi, P.P.; Barnabas, S.L.; Moodley, J.; Denny, L.; Coetzee, D.; et al. Female genital tract inflammation, HIV co-infection and persistent mucosal Human Papillomavirus (HPV) infections. Virology 2016, 493, 247-254. [CrossRef] 
13. Schettino, M.T.; Ammaturo, F.P.; Grimaldi, E.; Legnante, A.; Marcello, A.; Donnarumma, G.; Colacurci, N.; Torella, D. Persistent papillomavirus type-31 and type-45 infections predict the progression to squamous intraepithelial lesion. Taiwan J. Obstet. Gynecol. 2014, 53, 494-497. [CrossRef]

14. Khan, M.J.; Castle, P.E.; Lorincz, A.T.; Wacholder, S.; Sherman, M.; Scott, D.R.; Rush, B.B.; Glass, A.G.; Schiffman, M. The Elevated 10-Year Risk of Cervical Precancer and Cancer in Women With Human Papillomavirus (HPV) Type 16 or 18 and the Possible Utility of Type-Specific HPV Testing in Clinical Practice. J. Natl. Cancer Inst. 2005, 97, 1072-1079. [CrossRef]

15. Joura, E.A.; Giuliano, A.R.; Iversen, O.-E.; Bouchard, C.; Mao, C.; Mehlsen, J.; Moreira, E.D.; Ngan, Y.; Petersen, L.K.; LazcanoPonce, E.; et al. A 9-Valent HPV Vaccine against Infection and Intraepithelial Neoplasia in Women. N. Engl. J. Med. 2015, 372, 711-723. [CrossRef]

16. Harper, D.M.; Vierthaler, S.L. Next Generation Cancer Protection: The Bivalent HPV Vaccine for Females. ISRN Obstet. Gynecol. 2011, 2011, 1-20. [CrossRef]

17. Markowitz, L.E.; Tsu, V.; Deeks, S.L.; Cubie, H.; Wang, S.A.; Vicari, A.S.; Brotherton, J.M. Human Papillomavirus Vaccine Introduction-The First Five Years. Vaccine 2012, 30 (Suppl. 5), F139-F148. [CrossRef]

18. Delany-Moretlwe, S.; Kelley, K.F.; James, S.; Scorgie, F.; Subedar, H.; Dlamini, N.R.; Pillay, Y.; Naidoo, N.; Chikandiwa, A.; Rees, H. Human Papillomavirus Vaccine Introduction in South Africa: Implementation Lessons From an Evaluation of the National School-Based Vaccination Campaign. Glob. Health Sci. Pract. 2018, 6, 425-438. [CrossRef]

19. Botha, M.; Van Der Merwe, F.H.; Snyman, L.C.; Dreyer, G. The vaccine and cervical cancer screen (VACCS) project: Acceptance of human papillomavirus vaccination in a school-based programme in two provinces of South Africa. S. Afr. Med. J. 2015, 105, 40. [CrossRef]

20. Segondy, M.; Kelly, H.; Magooa, M.P.; Djigma, F.; Ngou, J.; Gilham, C.; Omar, T.; Goumbri-Lompo, O.; Michelow, P.; Doutre, S.; et al. Performance of careHPV for detecting high-grade cervical intraepithelial neoplasia among women living with HIV-1 in Burkina Faso and South Africa: HARP study. Br. J. Cancer 2016, 115, 425-430. [CrossRef]

21. Cuzick, J.; Myers, O.; Hunt, W.C.; Saslow, D.; Castle, P.E.; Kinney, W.; Waxman, A.; Robertson, M.; Wheeler, C.M.; on Behalf of the New Mexico HPV Pap Registry Steering Committee. Human papillomavirus testing 2007-2012: Co-testing and triage utilization and impact on subsequent clinical management. Int. J. Cancer 2015, 136, 2854-2863. [CrossRef]

22. Firnhaber, C.; Mayisela, N.; Mao, L.; Williams, S.; Swarts, A.; Faesen, M.; Levin, S.; Michelow, P.; Omar, T.; Hudgens, M.G.; et al. Validation of Cervical Cancer Screening Methods in HIV Positive Women from Johannesburg South Africa. PLoS ONE 2013, 8 , e53494. [CrossRef]

23. Ronco, G.; Dillner, J.; Elfström, K.M.; Tunesi, S.; Snijders, P.J.F.; Arbyn, M.; Kitchener, H.; Segnan, N.; Gilham, C.; Giorgi-Rossi, P.; et al. Efficacy of HPV-based screening for prevention of invasive cervical cancer: Follow-up of four European randomised controlled trials. Lancet 2014, 383, 524-532. [CrossRef]

24. Taku, O.; Meiring, T.L.; Gustavsson, I.; Phohlo, K.; Garcia-Jardon, M.; Mbulawa, Z.Z.A.; Businge, C.B.; Gyllensten, U.; Williamson, A.-L. Acceptability of self- collection for human papillomavirus detection in the Eastern Cape, South Africa. PLoS ONE 2020, 15, e0241781. [CrossRef] [PubMed]

25. Gustavsson, I.; Sanner, K.; Lindell, M.; Strand, A.; Olovsson, M.; Wikström, I.; Wilander, E.; Gyllensten, U. Type-specific detection of high-risk human papillomavirus (HPV) in self-sampled cervicovaginal cells applied to FTA elute cartridge. J. Clin. Virol. 2011, 51, 255-258. [CrossRef] [PubMed]

26. Herraez-Hernandez, E.; Alvarez, M.; Navarro-Bustos, G.; Esquivias, J.; Alonso, S.; Aneiros-Fernández, J.; Lacruz-Pelea, C.; Sanchez-Aguera, M.; Santamaria, J.S.; De Antonio, J.C.; et al. HPV Direct Flow CHIP: A new human papillomavirus genotyping method based on direct PCR from crude-cell extracts. J. Virol. Methods 2013, 193, 9-17. [CrossRef]

27. Ramogola-Masire, D.; McGrath, C.M.; Barnhart, K.T.; Friedman, H.M.; Zetola, N.M. Subtype Distribution of Human Papillomavirus in HIV-Infected Women With Cervical Intraepithelial Neoplasia Stages 2 and 3 in Botswana. Int. J. Gynecol. Pathol. 2011, 30, 591-596. [CrossRef]

28. McDonald, A.C.; Tergas, A.; Kuhn, L.; Denny, L.; Wright, T.C., Jr. Distribution of Human Papillomavirus Genotypes among HIV-Positive and HIV-Negative Women in Cape Town, South Africa. Front. Oncol. 2014, 4, 48. [CrossRef]

29. Van Aardt, M.C.; Dreyer, G.; Snyman, L.C.; Richter, K.L.; Becker, P.; Mojaki, S.M. Oncogenic and incidental HPV types associated with histologically confirmed cervical intraepithelial neoplasia in HIV-positive and HIV-negative South African women. S. Afr. Med. J. 2016, 106. [CrossRef]

30. Guan, P.; Howell-Jones, R.; Li, N.; Bruni, L.; De Sanjosé, S.; Franceschi, S.; Clifford, G.M. Human papillomavirus types in 115,789 HPV-positive women: A meta-analysis from cervical infection to cancer. Int. J. Cancer 2012, 131, 2349-2359. [CrossRef]

31. Menon, S.; Wusiman, A.; Boily, M.C.; Kariisa, M.; Mabeya, H.; Luchters, S.; Forland, F.; Rossi, R.; Callens, S.; Broeck, D.V. Epidemiology of HPV Genotypes among HIV Positive Women in Kenya: A Systematic Review and Meta-Analysis. PLoS ONE 2016, 11, e0163965. [CrossRef]

32. Sweet, K.; Bosire, C.; Sanusi, B.; Sherrod, C.J.; Kwatampora, J.; Waweru, W.; Mugo, N.; Kimani, J.; Ting, J.; Clark, J.; et al. Prevalence, incidence, and distribution of human papillomavirus types in female sex workers in Kenya. Int. J. STD AIDS 2020, 31, 109-118. [CrossRef] [PubMed]

33. Dovey de la Cour, C.; Guleria, S.; Nygård, M.; Trygvadóttir, L.; Sigurdsson, K.; Liaw, K.L.; Hortlund, M.; Lagheden, C.; Hansen, B.T.; Munk, C.; et al. Human papillomavirus types in cervical high-grade lesions or cancer among Nordic women-Potential for prevention. Cancer Med. 2019, 8, 839-849. [CrossRef] 
34. Pinheiro, M.; Gage, J.C.; Clifford, G.M.; Demarco, M.; Cheung, L.C.; Chen, Z.; Yeager, M.; Cullen, M.; Boland, J.F.; Chen, X.; et al. Association of HPV35 with cervical carcinogenesis among women of African ancestry: Evidence of viral-host interaction with implications for disease intervention. Int. J. Cancer 2020, 147, 2677-2686. [CrossRef] [PubMed]

35. Howitt, B.E.; Herfs, M.; Tomoka, T.; Kamiza, S.; Gheit, T.; Tommasino, M.; Delvenne, P.; Crum, C.P.; Milner, D. Comprehensive Human Papillomavirus Genotyping in Cervical Squamous Cell Carcinomas and Its Relevance to Cervical Cancer Prevention in Malawian Women. J. Glob. Oncol. 2017, 3, 227-234. [CrossRef]

36. Castellsagué, X.; Klaustermeier, J.; Carrilho, C.; Albero, G.; Sacarlal, J.; Quint, W.; Kleter, B.; Lloveras, B.; Ismail, M.R.; De Sanjosé, S.; et al. Vaccine-related HPV genotypes in women with and without cervical cancer in Mozambique: Burden and potential for prevention. Int. J. Cancer 2008, 122, 1901-1904. [CrossRef]

37. Okolo, C.A.; Franceschi, S.; Adewole, I.F.; Thomas, J.; Follen, M.; Snijders, P.J.F.; Meijer, C.J.L.M.; Clifford, G.M. Human papillomavirus infection in women with and without cervical cancer in Ibadan, Nigeria. Infect. Agents Cancer 2010, 5, 24. [CrossRef] [PubMed]

38. Denny, L.; Adewole, I.; Anorlu, R.; Dreyer, G.; Moodley, M.; Smith, T.; Snyman, L.C.; Wiredu, E.; Molijn, A.; Quint, W.; et al. Human papillomavirus prevalence and type distribution in invasive cervical cancer in sub-Saharan Africa. Int. J. Cancer 2014, 134, 1389-1398. [CrossRef] [PubMed]

39. Clifford, G.M.; De Vuyst, H.; Tenet, V.; Plummer, M.; Tully, S.; Franceschi, S. Effect of HIV Infection on Human Papillomavirus Types Causing Invasive Cervical Cancer in Africa. JAIDS J. Acquir. Immune Defic. Syndr. 2016, 73, 332-339. [CrossRef]

40. Van der Marel, J.; Berkhof, J.; Ordi, J.; Torné, A.; Del Pino, M.; van Baars, R.; Schiffman, M.; Wentzensen, N.; Jenkins, D.; Quint, W.G. Attributing oncogenic human papillomavirus genotypes to high-grade cervical neoplasia: Which type causes the lesion? Am. J. Surg. Pathol. 2015, 39, 496-504. [CrossRef]

41. Schmitt, M.; Depuydt, C.E.; Benoy, I.; Bogers, J.P.; Antoine, J.; Arbyn, M.; Pawlita, M.; on behalf of the VALGENT Study Group. Multiple Human Papillomavirus Infections with High Viral Loads Are Associated with Cervical Lesions but Do Not Differentiate Grades of Cervical Abnormalities. J. Clin. Microbiol. 2013, 51, 1458-1464. [CrossRef] [PubMed]

42. Kaliff, M.; Sorbe, B.; Mordhorst, L.B.; Helenius, G.; Karlsson, M.G.; Lillsunde-Larsson, G. Findings of multiple HPV genotypes in cervical carcinoma are associated with poor cancer-specific survival in a Swedish cohort of cervical cancer primarily treated with radiotherapy. Oncotarget 2018, 9, 18786-18796. [CrossRef] [PubMed]

43. Munagala, R.; Donà, M.G.; Rai, S.N.; Jenson, A.B.; Bala, N.; Ghim, S.J.; Gupta, R.C. Significance of multiple HPV infection in cervical cancer patients and its impact on treatment response. Int. J. Oncol. 2009, 34, 263-271. [PubMed]

44. De Vuyst, H.; Chung, M.H.; Baussano, I.; Mugo, N.R.; Tenet, V.; van Kemenade, F.J.; Rana, F.S.; Sakr, S.R.; Meijer, C.J.; Snijders, P.J.; et al. Comparison of HPV DNA testing in cervical exfoliated cells and tissue biopsies among HIV-positive women in Kenya. Int. J. Cancer 2013, 133, 1441-1446. [CrossRef]

45. Bruni, L.; Diaz, M.; Castellsagué, X.; Ferrer, E.; Bosch, F.X.; De Sanjosé, S. Cervical Human Papillomavirus Prevalence in 5 Continents: Meta-Analysis of 1 Million Women with Normal Cytological Findings. J. Infect. Dis. 2010, 202, 1789-1799. [CrossRef]

46. Monsonego, J.; Cox, J.T.; Behrens, C.; Sandri, M.; Franco, E.L.; Yap, P.-S.; Huh, W. Prevalence of high-risk human papilloma virus genotypes and associated risk of cervical precancerous lesions in a large U.S. screening population: Data from the ATHENA trial. Gynecol. Oncol. 2015, 137, 47-54. [CrossRef]

47. Tornesello, M.L.; Giorgi Rossi, P.; Buonaguro, L.; Buonaguro, F.M. Human Papillomavirus Infection and Cervical Neoplasia among Migrant Women Living in Italy. Front. Oncol. 2014, 4, 31. [CrossRef]

48. Hildesheim, A.; Wang, S.S. Host and viral genetics and risk of cervical cancer: A review. Virus Res. 2002, 89, 229-240. [CrossRef]

49. Serrano, B.; Alemany, L.; De Ruíz, P.A.; Tous, S.; Lima, M.A.; Bruni, L.; Jain, A.; Clifford, G.M.; Qiao, Y.L.; Weiss, T.; et al. Potential impact of a 9-valent HPV vaccine in HPV-related cervical disease in 4 emerging countries (Brazil, Mexico, India and China). Cancer Epidemiol. 2014, 38, 748-756. [CrossRef]

50. Garland, S.M.; Pitisuttithum, P.; Ngan, H.Y.S.; Cho, C.-H.; Lee, C.-Y.; Chen, C.-A.; Yang, Y.C.; Chu, T.-Y.; Twu, N.-F.; Samakoses, R.; et al. Efficacy, Immunogenicity, and Safety of a 9-Valent Human Papillomavirus Vaccine: Subgroup Analysis of Participants From Asian Countries. J. Infect. Dis. 2018, 218, 95-108. [CrossRef]

51. Huh, W.K.; Joura, E.A.; Giuliano, A.R.; Iversen, O.-E.; De Andrade, R.P.; Ault, K.A.; Bartholomew, D.; Cestero, R.M.; Fedrizzi, E.N.; Hirschberg, A.L.; et al. Final efficacy, immunogenicity, and safety analyses of a nine-valent human papillomavirus vaccine in women aged 16-26 years: A randomised, double-blind trial. Lancet 2017, 390, 2143-2159. [CrossRef]

52. Ruiz-Sternberg, Á.M.; Moreira, E.D., Jr.; Restrepo, J.A.; Lazcano-Ponce, E.; Cabello, R.; Silva, A.; Andrade, R.; Revollo, F.; Uscanga-Sánchez, S.R.; Victori, A.; et al. Efficacy, immunogenicity, and safety of a 9-valent human papillomavirus vaccine in Latin American girls, boys, and young women. Papillomavirus Res. 2018, 5, 63-74. [CrossRef]

53. Kreimer, A.R.; Struyf, F.; Del Rosario-Raymundo, M.R.; Hildesheim, A.; Skinner, S.R.; Wacholder, S.; Garland, S.M.; Herrero, R.; David, M.P.; Wheeler, C.M.; et al. Efficacy of fewer than three doses of an HPV-16/18 AS04-adjuvanted vaccine: Combined analysis of data from the Costa Rica Vaccine and PATRICIA Trials. Lancet Oncol. 2015, 16, 775-786. [CrossRef]

54. Skinner, S.R.; Apter, D.; De Carvalho, N.; Harper, D.M.; Konno, R.; Paavonen, J.; Romanowski, B.; Roteli-Martins, C.; Burlet, N.; Mihalyi, A.; et al. Human papillomavirus (HPV)-16/18 AS04-adjuvanted vaccine for the prevention of cervical cancer and HPV-related diseases. Expert Rev. Vaccines 2016, 15, 367-387. [CrossRef]

55. Malagón, T.; Drolet, M.; Boily, M.-C.; Franco, E.L.; Jit, M.; Brisson, J.; Brisson, M. Cross-protective efficacy of two human papillomavirus vaccines: A systematic review and meta-analysis. Lancet Infect. Dis. 2012, 12, 781-789. [CrossRef] 
56. Bogaards, J.A.; Van Der Weele, P.; Woestenberg, P.J.; Van Benthem, B.H.B.; King, A.J. Bivalent Human Papillomavirus (HPV) Vaccine Effectiveness Correlates With Phylogenetic Distance From HPV Vaccine Types 16 and 18. J. Infect. Dis. 2019, 220, 1141-1146. [CrossRef]

57. Tsang, S.H.; Sampson, J.N.; Schussler, J.; Porras, C.; Wagner, S.; Boland, J.; Cortes, B.; Lowy, D.R.; Schiller, J.T.; Schiffman, M.; et al. Durability of Cross-Protection by Different Schedules of the Bivalent HPV Vaccine: The CVT Trial. J. Natl. Cancer Inst. 2020, 112, 1030-1037. [CrossRef] [PubMed]

58. Brown, D.R.; Kjaer, S.K.; Sigurdsson, K.; Iversen, O.; Hernandez-Avila, M.; Wheeler, C.M.; Perez, G.; Koutsky, L.A.; Tay, E.H.; Garcia, P.; et al. The Impact of Quadrivalent Human Papillomavirus (HPV; Types 6, 11, 16, and 18) L1 Virus-Like Particle Vaccine on Infection and Disease Due to Oncogenic Nonvaccine HPV Types in Generally HPV-Naive Women Aged 16-26 Years. J. Infect. Dis. 2009, 199, 926-935. [CrossRef] 